\title{
1990 Annual Meeting of Chinese Society for Materials Science Held in April
}

The 1990 Annual Meeting of the Chinese Society for Materials Science (CSMS) presented 326 papers with attendance of 516 , making it the Society's largest annual meeting to date. The meeting, held April 27-29 in Hsinchu, Taiwan at National Tsing Hwa University and National Chiao Tung University, respectively, was hosted by CSMS President Dr. Otto C.C. Lin and organized by Conference Chairman Dr. P.T. Wu.

Prof. R.P.H. Chang, director of the Materials Research Center at Northwestern University, was the keynote speaker. Chang, one of the founders and newly elected chairman of the International Materials Research Committee and also past president of the Materials Research Society, specializes in diamond film research.

Adding organizers and exhibitors, a total of 653 people were involved in the activities of the meeting. Among the dignitaries on hand were Dr. K.T. Li, senior adviser to the president of the country; Dr. C.S. Liu, president of National Tsing Hwa University; and Dr. Daniel T.L. Yuan, president of National Chiao Tung University.

The technical program spanned developments in metals, electronic materials, magnetic and superconducting materials, ceramics, polymers and composites, materials protection, and new materials. The invited, oral and poster papers were compiled into a two-volume proceedings.

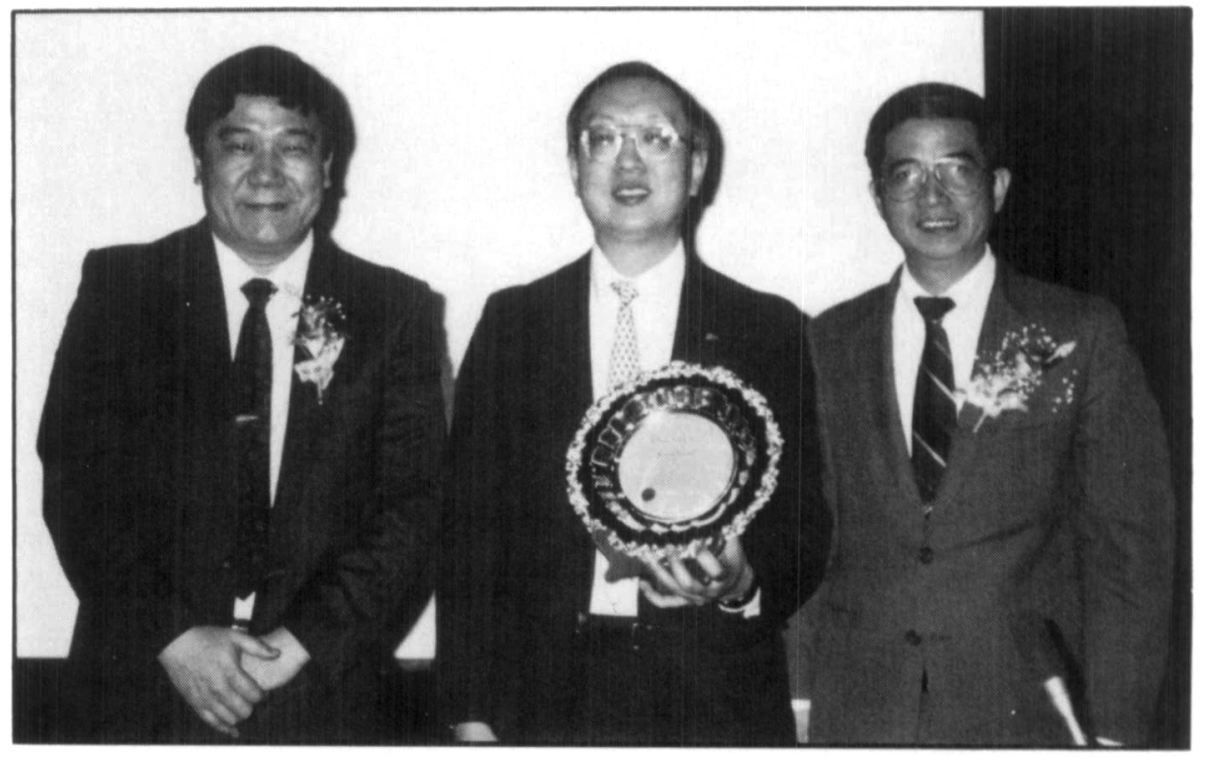

CSMS President Otto C.C. Lin (left) and Conference Chainman P.T. Wu (right) present a plaque to Prof. R.P.H. Chang, keynote speaker at the 1990 CSMS Annual Meeting.

\section{K.T. Li Receives Lu Award}

Dr. K.T. Li was named recipient of the 1990 Dr. C.H. Lu Award, the country's highest materials science honor. $\mathrm{Li}$, who has more than 50 years of public service, has made numerous contributions to ROC's economy and science and has been

\section{Prof. Chang (left) visits President Lee in Taipei}

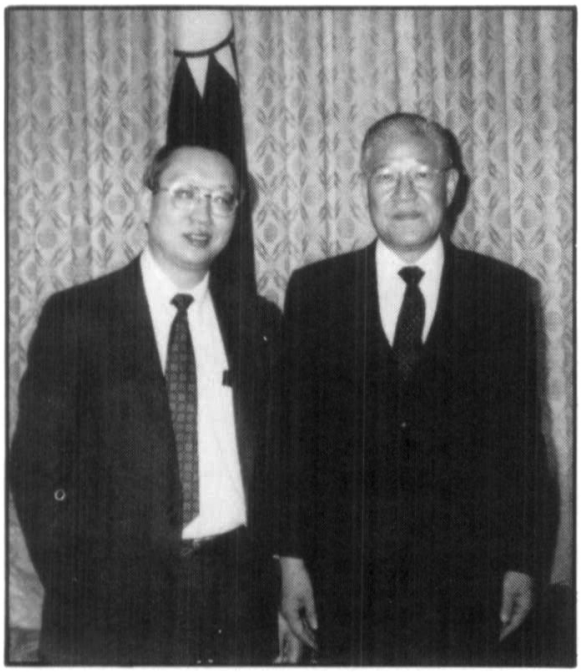

During his recent visit to Taiwan, Prof. R.P.H. Chang chair of the International Materials Research Committee and director of the Materials Research Center at Northwestern University, had an opportunity to meet with President Lee Teng-Hui of the Republic of China. During their conversation, President Lee pointed out that his government provides strong support for materials research and technology. Over the next five years, his government plans to spend $\$ 40$ million in high temperature superconductivity research and development. Prof. Chang also visited the Materials Research Laboratories of the Industrial Technology Research Institute and the Materials Research Laboratory of the Chung San Institute of Science and Technology. the driving force behind materials science advances in the country. The award recognized his many contributions to the field.

\section{CSMS-22 Years of Service to Materials Science}

The Chinese Society for Materials Science, established September 15, 1968, is one of the oldest scientific organizations in China and has 1,770 members. CSMS is an active participant in the advancement of materials science on both national and international levels. In 1987 CSMS helped to raise funds for the establishment of the Morris Cohen Materials Science and Engineering Professorship at the Massachusetts Institute of Technology. In 1989, it assisted in the establishment of the International Materials Research Committee and is one of the founding bodies.

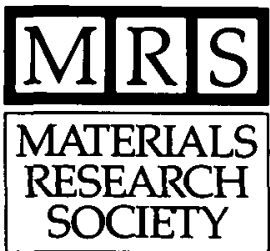

